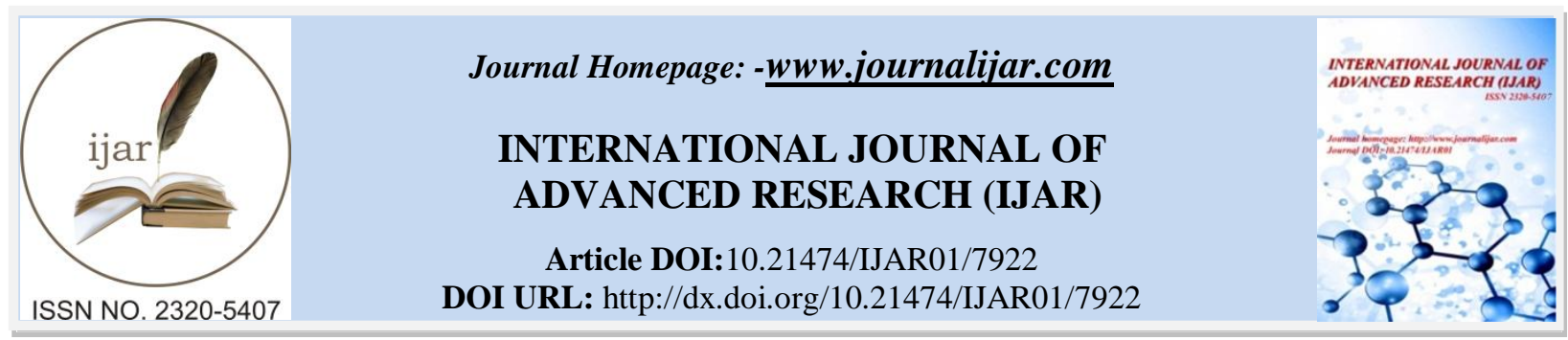

RESEARCH ARTICLE

\title{
THE CAUSAL RELATIONSHIP BETWEEN INFANT MORTALITY AND FERTILITY RATE IN GHANA: ECONOMETRIC AND TIME SERIES ANALYSIS.
}

\author{
Abdul-Hamid Ahmed ${ }^{1}$ and Musilimu Muftawu,* \\ 1. International Economics, Gazi University, Ankara, Turkey. \\ 2. Health Services Management, Ankara University, Ankara, Turkey.
}

\section{Manuscript Info}

Manuscript History

Received: 14 August 2018

Final Accepted: 16 September 2018

Published: October 2018

\section{Keywords:}

infant mortality rate, total fertility rate, crude birth rate, Causality, Ghana.

\begin{abstract}
Infant mortality has been a major public health issue from time immemorial. Understanding the association between infant and childhood mortality and total fertility is essential especially to countries that are currently undergoing demographic transition. The study therefore examined the relationship between infant mortality and fertility rate in Ghana by using a time series data stemming from 1960 to 2016.The research employed Granger causality test, error correction model (ECM) and multiple correlation coefficient to deduce the association between infant and childhood mortality and fertility rate of women in Ghana. The results of the Pairwise Granger causality test reveals a unidirectional causality and hence proved to be dependent on total fertility rate (TFR) and ECM shows a positive long-run relationship among the variables. In conclusion, the rate of increase or decrease in total fertility will leads to a tremendous increase or decrease in infant and childhood mortality. In this study, the rate of decline on Ghana's total fertility rate led to a sharp reduction on infant and childhood mortality rate from 124.2 per 1000 live birth in 1960 to 37.2 per 1000 live births in 2016 and this might be expected as hording behavior diminishes overtime.
\end{abstract}

Copy Right, IJAR, 2018,. All rights reserved.

\section{Introduction:-}

Understanding the relationship between infant mortality and fertility is vital, especially to countries that are currently undergoing demographic transition (J.M, 1977); and for designing effective policies aim at reducing child mortality and fertility (Soest \& Saha, 2018). The demographic transition theory postulates a strong correlation between infant mortality and fertility (Kirk, 1996). Physiological changes and replacement effects are two ways by which infant mortality affects fertility. Physiologically, breastfeeding is interrupted by death, shortening postpartum insusceptibility, resulting in early conception by the mother(van Ginneken, Bairagi, de Francisco, Sarder, \& Vaughan, 1998). The replacement effect arises when couple replaces a lost child because of a desire family size (Trussell \& Olsen, 1983).

Infant and child mortality is a huge public health problem, especially in the developing nations. According to the World Health Organization (WHO), 75\% of all under-five years' death (4.1 million) in 2017 occurred within the first year of live. Infant mortality risk in the WHO African Region was six times hire higher than that in the WHO 
European Region; 51 per 1000 live births vs 8 per 1000 live births respectively. Globally, infant mortality rate has decreased over the past 27 years (1990 to 2017) from 65 deaths per 1000 live births to 29 deaths per 1000 live births, representing a declined in annual infant deaths of 8.8 million in 1990 to 4.1 million in 2017 (WHO, 2018b). In 2017 alone, 5.4 million children under age five died (WHO, 2018c). Preterm birth complications, acute respiratory infections, intrapartum-related complications, congenital anomalies and diarrhea, were the leading causes of death under-five children (WHO, 2018a).

Fertility rate which is defined as the total birth per woman, has also seen a global decrease over the years, from 4.9 in 1960 to 2.5 in 2016. Sub-Saharan Africa has the highest current rate of 4.85 with Ghana having a rate of 3.9 (The World Bank, 2017).

Specific fertility behaviors such as preterm birth, birth intervals, and post term delivery have been found to be associated with child's death risk in different independent studies (Asefa, Drewett, \& Tessema, 2000; Madise, Nyarko, \& Diamond, 2016; Rahman \& Ansari, 1800).

Further research on infant mortality and fertility focused on econometric and time series data analysis. For instance, Hussein (Hussein, 1993) examines the time series analysis for forecasting both fertility and mortality levels in Egypt until 2010 using autoregressive integrated moving average (ARIMA) model to analyze a time series of crude birth rate (CBR) and crude death rate (CDR) in Egypt over the period 1992-2010. His procedure predicts a steady, but slow decline in the crude death rate coinciding with the original crude death rate time series since World War II while the predicted values for crude birth rate continue to move up and down in keeping pace with the original data reaching approximately 31 per 1000 . Another time series analysis in the united states from the 1850 s to the $1940 \mathrm{~s}$ gives credence to the view that modest direct reduction in fertility can be expected from reduction in infant and childhood development (Haines, 1998). Galloway et al (Galloway, Lee Ronald D, \& Hammel, 1998) analyzedinfant mortality and fertility transition based on macro evidence from Europe and new findings from Prussia. They use aggregate data from 1875 to 1910 and fixed effects models with instrumental variables to measure the impact of infant mortality on fertility and the reverse. Their findings revealed a positive association between them. Another study that compared under five mortality and fertility rate for some selected sub-Saharan African countries revealed a positive correlation with a Pearson's correlation coefficient of 0.76 (Madise et al., 2016).

Even though there is an extensive discussions in the literature on the theoretical pathways through which infant mortality is associated with fertility, Palloni and Rafalimanana argue that the empirical relationship between the two remain unclear(Palloni \& Rafalimanana, 1999). In light of this, our study dwells on the effect of total fertility rate (TFR) and crude birth rate on infant mortality rate (IMR) using econometrics and time series data analysis.

The figure 1. Below depicts the trend of infant mortality rate (IMR), total fertility rate (TFR) and crude birth rate (CBR) in Ghana over a period of six decades that is from the year 1960 to 2016.

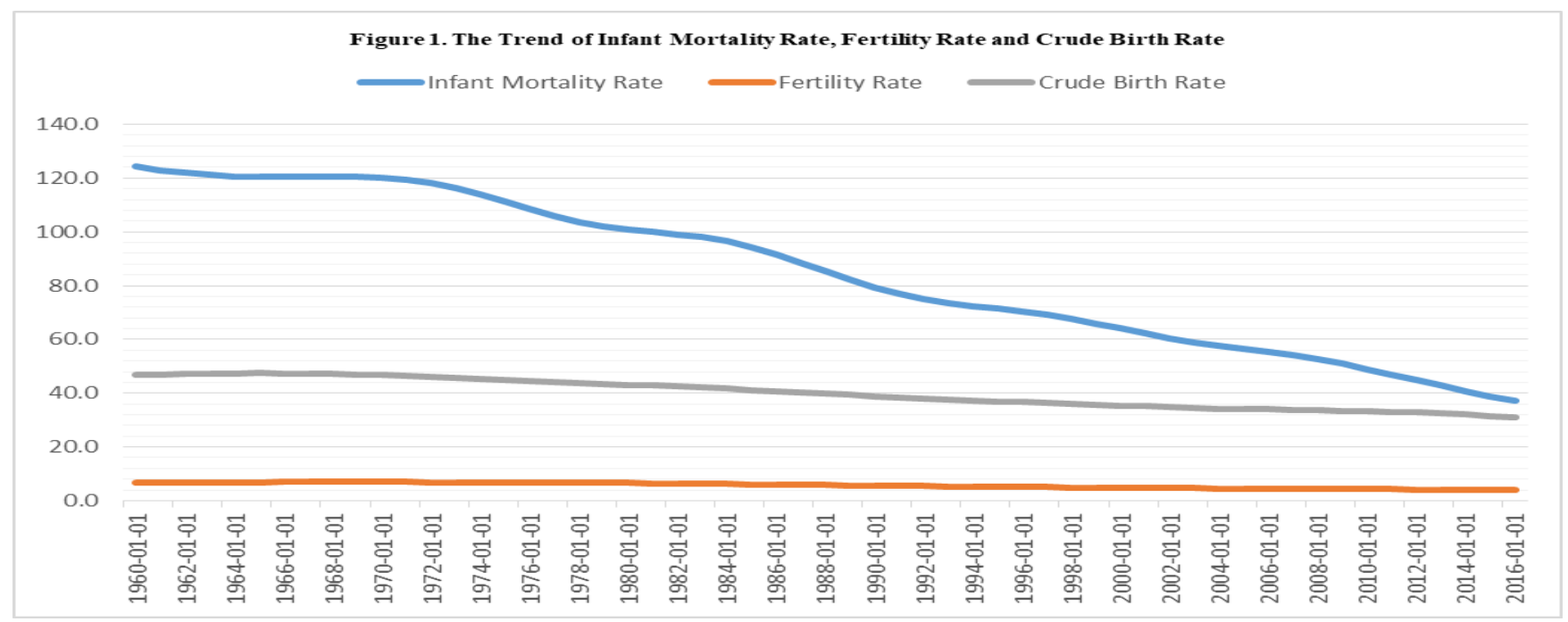

Source: Researchers' Sketch, October 2018 
To establish the facts and understand the trend logically and economically, this research paper critically evaluate the effect of total fertility rate (TFR), crude birth rate (CBR) on infant mortality rate (IMR) and the vice versa by taking in to consideration the unidirectional causality, correlation and the long-run relationship among them.

\section{Data and Research Methodology}

The primary research method for this study is literature review and Conceptual modeling. The methodology specifically describes the data collection process and the procedure for the data analysis.

\section{Data Set and Analysis}

The study employed secondary data from World Bank (WB). That is estimates developed by the United Nations Inter-agency Group for Child Mortality and United Nations Population Division (UNPD), published in October, 2018 by the Federal Reserve Economic Data (FRED). The data constitute infant mortality rate (IMR), total fertility rate (TFR) and crude birth rate (CBR) of Ghana stemming from 1960 to 2016. This research spans for more than a period of six decades. The secondary data sourced from World Bank through the United Nations Population Divisions and estimates developed by the United Nations Inter-agency Group for Child Mortality was analysed using Microsoft excel and econometrics views 8.0.

Table 3.1:-Operationalization of the Study Variables

\begin{tabular}{|c|c|c|}
\hline Variables & Measurements & Units \\
\hline \multicolumn{3}{|l|}{ Dependent Variable } \\
\hline IMR & $\begin{array}{l}\text { Infant mortality rate is the number of infants dying before } \\
\text { reaching one year of age, per } 1,000 \text { live births in a given year. }\end{array}$ & $\begin{array}{l}\text { Number per } \\
1,000 \text { Live } \\
\text { Births }\end{array}$ \\
\hline \multicolumn{3}{|l|}{ Independent Variables } \\
\hline Total Fertility Rate (TFR) & $\begin{array}{l}\text { Total fertility rate represents the number of children that would } \\
\text { be born to a woman if she were to live to the end of her } \\
\text { childbearing years and bear children in accordance with } \\
\text { current age-specific fertility rates. }\end{array}$ & $\begin{array}{l}\text { Births per } \\
\text { Woman }\end{array}$ \\
\hline Crude Birth Rate & $\begin{array}{l}\text { Crude birth rate indicates the number of live births occurring } \\
\text { during the year, per } 1,000 \text { population estimated at midyear. } \\
\text { Subtracting the crude death rate from the crude birth rate } \\
\text { provides the rate of natural increase, which is equal to the rate } \\
\text { of population change in the }\end{array}$ & $\begin{array}{l}\text { Births per } \\
1,000 \\
\text { People }\end{array}$ \\
\hline
\end{tabular}

Source: World Bank(World Bank, 2018a, 2018b, 2018c)

\section{Model Specification}

The explained variables in the model is the infant mortality rate (IMR). The major indicator of the explanatory variables were total fertility rate and crude birth rate. In this study, we employed the following baseline model.

$\mathrm{IMR}_{\mathrm{t}}=\beta_{0}+\beta_{1} \mathrm{TFR}_{\mathrm{t}}+\beta_{2} \mathrm{CBR}_{\mathrm{t}}+\varepsilon_{\mathrm{t}}$

Where:

$\mathrm{IMR}_{\mathrm{t}}=$ Infant Mortality Rate at time $\mathrm{t}$

$\mathrm{TFR}_{t}=$ Total Fertility Rate at time $\mathrm{t}$

$\mathrm{CBR}=$ Crude birth rate at time $\mathrm{t}$ and $\varepsilon_{\mathrm{t}}=$ pure white noise error term meaning that there could be other variables that influence infant mortality rate aside the total fertility and crude birth rate in Ghana.

\section{Testing For Granger- Causality}

With the fundamental understanding of the existence of long-run relationship between two economic variables implies at least unidirectional Granger causality, the research employed data from World Bank to tests for Granger causality. The logic behind this causality is to check whether changes in infant mortality rate (IMR) in Ghana has a well-defined paths. In other words, to find out whether changes in the levels of explanatory variables such as total fertility rate (TFR) and crude birth rate (CBR) in Ghana is induce by the level of infant mortality rate and the vice versa. In short, explaining the Granger causality test, the study considered asking the usual macroeconomics question of: Is it infant mortality rate of Ghana that "causes" total fertility rate and crude birth rate of Ghana to change $\left(I M R_{t} \rightarrow T F R_{t}\right.$ and $\left.C B R_{t}\right)$ ? Or is total fertility rate and crude birth rate of Ghana cause infant mortality rate 
in the dynamic process $\left(T F R_{t} \rightarrow I M R_{t}\right)$, in which the arrows give causality direction. Critical assumption of the Granger causality test is that the information relevant to the prediction of the respective variables is contained solely in the time series data on these variables(Granger, 1969). Granger-causality tests examines the degree to which both current and past values of infant mortality rate changes explains the current change in the total fertility rate pattern and also, how both current and past fluctuations in the total fertility rate (TFR) affects changes in current infant mortality rate (IMR). The test involves estimating the following pair of regressions:

$$
\begin{aligned}
I M R_{t} & =\sum_{i=1}^{n} \alpha_{i} \operatorname{TFR}_{t-i}+\sum_{i=1}^{n} \beta_{j} I M R_{t-j}+\varepsilon_{1 t} \ldots \ldots \ldots \ldots \ldots \\
\operatorname{TFR}_{t} & =\sum_{i=1}^{n} \emptyset_{i} T F R_{t-i}+\sum_{i=1}^{n} \delta_{j} I M R_{t-j}+\varepsilon_{2 t} \ldots \ldots \ldots \ldots \ldots
\end{aligned}
$$

where IMR $R_{t}$ Constitute the elements of crude death rate, $\boldsymbol{T} \boldsymbol{F} \boldsymbol{R}_{\boldsymbol{t}}$ is the total fertility rate and $\boldsymbol{\varepsilon}_{1 \boldsymbol{t}}$ and $\varepsilon_{2 t}$ are error terms with respect to time t.

$$
F_{C a l}=\frac{\left(R S S_{R}-R S S_{U R}\right) / m}{\left(R S S_{U R}\right) /(n-k)}
$$

The F-test shows the F-distribution with $\mathrm{m}$ and $(\mathrm{n}-\mathrm{k})$ degrees of freedom, $\mathrm{m}$ is the number of lagged terms, $\mathrm{k}$ is the number of parameter estimated in the unrestricted regression, $R S S_{R}$ is the residual sum of squares from the restricted models and $R S S_{U R}$ is the residual sum of squares from the unrestricted model.

Where the stochastic terms are assumed to be uncorrelated over a period of the study. A unidirectional Granger causality of or is proved by an F-test on the null hypothesis that the coefficients of in equation (2) and in equation (3) equal zero. i.e., while the alternative hypothesis states that; at least one of the coefficients is not equal to zero. Passing decision is based on the value of the calculated and critical F. If critical F-value is less than the computed F value, we reject null hypothesis, explaining causality relationship among the stated variables above.

\section{Statement of Hypotheses}

The following specific hypotheses were tested using econometric views (e-views) 8.0 to establish the Granger causality between infant mortality rate and the total fertility rate in Ghana:

1. the null hypothesis that infant mortality rate (IMR) does not Granger cause total fertility rate (TFR), or

2. the null hypothesis that the total fertility rate (TFR) does not Granger cause infant mortality rate (IMR).

3. the alternative hypothesis that infant mortality rate does Granger cause total fertility rate in the Ghanaian economy. Or

4. the alternate hypothesis that the total fertility rate (TFR) does Granger cause infant mortality rate (IMR).

\section{Testing for Error Correction Model (ECM): Short-Run Analysis}

The idea of Error Correction Model (ECM) is based on the axiom of the long-run equilibrium relationship among econometric variables. The ECM is useful in dealing with the problems of non-stationary time series and spurious correlation (Thomas, 1997). A simple First-order ECM is given by:

1. Suppose that the long-run or equilibrium relationship between infant mortality rate (IMR) and total fertility rate (TFR) is $I M R_{t}=K T F R_{t}^{\beta_{1}} \ldots \ldots \ldots \ldots$ (5) where $\mathrm{K}$ and $\beta_{1}$ are constants. $\beta_{1}$ Is the long-run elasticity of IMR with respect to TFR. Now, by transforming the natural logarithms of the variables, we rewrite the equation (5) as $I M R_{t}=\beta_{0}^{*}+\beta_{1} T F R_{t}$

2. By measuring the extent of disequilibrium between IMR and TFR, the disequilibrium is observe as a short-run or disequilibrium relationship involving lagged values of TFR and IMR. This is given by $I M R_{t}=\beta_{0}+$ $\beta_{1} T F R_{t}+\beta_{2} T F R_{t-1}+\mu I M R_{t-1}+\varepsilon_{t}$

3. The fact that the error correction coefficient has a negative sign means that the shocks will come to the balance in the long-run. The delay value (1) of the error terms obtained from the $1^{\text {st }}$ equation is added to the calculus as an explanatory variable in equation (7). This is transform by:

4. $\Delta I M R_{t}=\beta_{0}+\beta_{1} \Delta I M R_{-1 t}+\beta_{2} T F R_{t}+e c m+\varepsilon_{t-1} \ldots \ldots \ldots \ldots \ldots$ (8) Where $\Delta$ is the first difference equation given by (1), $\beta_{0}, \beta_{1}$, and $\beta_{2}$ is the parameter estimates in the intersection and independent variables, respectively , ecm represents the error correction term and $\varepsilon_{t}$ is the pure white noise term. 


\section{Empirical Results and Discussion:-}

Results for Pairwise Granger Causality Test

The pairwise causality result in Table 3.1 reveals that, the null hypothesis of IMR does not Granger cause TFR could not be accepted since the F-statistics in any of the events is more than the probability values at that event and pvalue is also less than $5 \%$. Hence, there is a unidirectional causality between infant mortality rate (IMR) and total fertility rate (TFR) with the lagged values of 2 . Conversely, the causality test of IMR to CBR and CBR to IMR indicates that IMR does Granger cause CBR and the vice versa, suggesting a causal relationship between the two variables since their probability values are less than 5\%, so we reject the null hypothesis. In effect, infant mortality rate (IMR) does Granger cause the total fertility rate (TFR) and crude birth rate (CBR) and hence causal relationship among them. However, among the explanatory variables, TFR does not Granger cause CBR and the reverse is the case as indicated in the table 3.1 below.

Table 3.1:-Results of Pairwise Granger Causality Test

\begin{tabular}{|l|l|l|l|l|l|}
\hline Statement of Null Hypothesis & $\begin{array}{l}\text { No. } \\
\text { of } \\
\text { Lags }\end{array}$ & $\begin{array}{l}\text { No. of } \\
\text { Observations }\end{array}$ & F-Statistics & P-Value & Decision \\
\hline $\begin{array}{l}\text { IMR does not Granger Cause } \\
\text { TFR }\end{array}$ & 2 & 55 & 7.13989 & 0.0019 & Granger Causality \\
\hline $\begin{array}{l}\text { TFR does not Granger Cause } \\
\text { IMR }\end{array}$ & 2 & 55 & 1.94772 & 0.1533 & No Granger Causality \\
\hline $\begin{array}{l}\text { IMR does not Granger Cause } \\
\text { CBR }\end{array}$ & 2 & 55 & 10.6185 & 0.0001 & Granger Causality \\
\hline $\begin{array}{l}\text { CBR does not Granger Cause } \\
\text { IMR }\end{array}$ & 2 & 55 & 8.25155 & 0.0008 & Granger Causality \\
\hline $\begin{array}{l}\text { TFR does not Granger Cause } \\
\text { CBR }\end{array}$ & 2 & 55 & 14.0139 & 1. E-05 & No Granger Causality \\
\hline $\begin{array}{l}\text { CBR does not Granger Cause } \\
\text { FTR }\end{array}$ & 2 & 55 & 13.5829 & 2.E-05 & No Granger Causality \\
\hline
\end{tabular}

Source: Author's Computation, 2018

According to the results of the pairwise Granger causality test, in the long run, the direction of causality between the infant mortality rate (IMR) and total fertility rate (TFR) is straightforward from the IMR to the TFR and IMR is does influence by TFR.

\section{Results of Error Correction Model (ECM)}

This section presents the tabular analysis of the short-term relationship between infant mortality rate, total fertility rate and crude birth rate using error correction model from 1960 to 2016 in Ghana using data from World Bank (WB).

Table 3.2.:-Error Correction Model

\begin{tabular}{|c|c|c|c|c|}
\hline \multicolumn{5}{|c|}{$\begin{array}{l}\text { Dependent Variable: D(INFANT_MORTALITY_RATE) } \\
\text { Method: Least Squares } \\
\text { Date: } 10 / 05 / 18 \text { Time: } 10: 22 \\
\text { Sample (adjusted): } 19652016 \\
\text { Included observations: } 52 \text { after adjustments }\end{array}$} \\
\hline Variable & Coefficient & Std. Error & $\mathrm{t}$-Statistic & Prob. \\
\hline C & -0.197804 & 0.068836 & -2.873543 & 0.0064 \\
\hline D(INFANT_MORTALITY_RATE(-1)) & 1.208283 & 0.224832 & 5.374165 & 0.0000 \\
\hline D(INFANT_MORTALITY_RATE(-2)) & -0.016607 & 0.375299 & -0.044251 & 0.9649 \\
\hline D(INFANT_MORTALITY_RATE(-3)) & -0.523485 & 0.201148 & -2.602482 & 0.0128 \\
\hline D(TOTAL_FERTILITY_RATE(-1)) & -13.96284 & 18.26412 & -0.764495 & 0.4489 \\
\hline D(TOTAL_FERTILITY_RATE(-2)) & 26.30183 & 33.72243 & 0.779951 & 0.4399 \\
\hline
\end{tabular}




\begin{tabular}{|crrrr}
\hline D(TOTAL_FERTILITY_RATE(-3)) & -11.40224 & 16.69449 & -0.682994 & 0.4985 \\
D(CRUDE_BIRTH_RATE(-1)) & 7.205132 & 3.095686 & 2.327475 & 0.0250 \\
D(CRUDE_BIRTH_RATE(-2)) & -13.37116 & 5.914892 & -2.260592 & 0.0292 \\
D(CRUDE_BIRTH_RATE(-3)) & 7.122575 & 3.074411 & 2.316728 & 0.0256 \\
ECT(-1) & -0.091564 & 0.290428 & -0.315272 & 0.7542 \\
\hline \hline & 0.982217 & Mean dependent var & -1.603846 \\
R-squared & 0.977880 & S.D. dependent var & 0.835009 \\
Adjusted R-squared & 0.124189 & Akaike info criterion & -1.148616 \\
S.E. of regression & 0.632341 & Schwarz criterion & -0.735853 \\
Sum squared resid & 40.86401 & Hannan-Quinn criter. & -0.990372 \\
Log likelihood & 226.4604 & Durbin-Watson stat & 1.976732 \\
F-statistic & 0.000000 & & \\
Prob(F-statistic) & & & \\
\hline \hline
\end{tabular}

Source: Researchers' Computation, 2018

Table 3.2.1:Breusch-Godfrey Serial Correlation LM Test:

\begin{tabular}{|c|c|c|c|}
\hline F-statistic & 0.268383 & Prob. F(3,38) & 0.8478 \\
\hline Obs*R-squared & 1.078923 & Prob. Chi-Square(3) & 0.7822 \\
\hline
\end{tabular}

Test Equation:

Dependent Variable: RESID

Method: Least Squares

Date: 10/05/18 Time: 10:23

Sample: 19652016

Included observations: 52

Presample missing value lagged residuals set to zero.

\begin{tabular}{crrrr}
\hline \hline Variable & Coefficient & Std. Error & t-Statistic & Prob. \\
\hline \hline C & -0.054626 & 0.093956 & -0.581405 & 0.5644 \\
D(INFANT_MORTALITY_RATE(-1)) & -0.272346 & 0.414325 & -0.657325 & 0.5149 \\
D(INFANT_MORTALITY_RATE(-2)) & 0.459817 & 0.706719 & 0.650637 & 0.5192 \\
D(INFANT_MORTALITY_RATE(-3)) & -0.248793 & 0.381519 & -0.652112 & 0.5183 \\
D(TOTAL_FERTILITY_RATE(-1)) & 4.784724 & 20.07439 & 0.238350 & 0.8129 \\
D(TOTAL_FERTILITY_RATE(-2)) & -8.086142 & 36.84480 & -0.219465 & 0.8275 \\
D(TOTAL_FERTILITY_RATE(-3)) & 3.947254 & 18.20085 & 0.216872 & 0.8295 \\
D(CRUDE_BIRTH_RATE(-1)) & -0.395481 & 3.376058 & -0.117143 & 0.9074 \\
D(CRUDE_BIRTH_RATE(-2)) & 0.691272 & 6.413464 & 0.107785 & 0.9147 \\
D(CRUDE_BIRTH_RATE(-3)) & -0.266007 & 3.313891 & -0.080270 & 0.9364 \\
ECT(-1) & 0.251446 & 0.612251 & 0.410691 & 0.6836 \\
RESID(-1) & 0.058820 & 0.422781 & 0.139127 & 0.8901 \\
RESID(-2) & -0.151521 & 0.278684 & -0.543700 & 0.5898 \\
RESID(-3) & 0.216669 & 0.251203 & 0.862527 & 0.3938 \\
\hline \hline & 0.020749 & Mean dependent var & $2.43 E-17$ \\
R-squared & -0.314259 & S.D. dependent var & 0.111350 \\
Adjusted R-squared & 0.127653 & Akaike info criterion & -1.054198 \\
S.E. of regression & 0.619221 & Schwarz criterion & -0.528863 \\
Sum squared resid & 41.40915 & Hannan-Quinn criter. & -0.852797 \\
Log likelihood & 0.061935 & Durbin-Watson stat & 1.990810 \\
F-statistic & &
\end{tabular}


Prob(F-statistic)

Source: Researchers' Computation, 2018

Figure 3 Stability Diagnostic

Test- Cusum Test

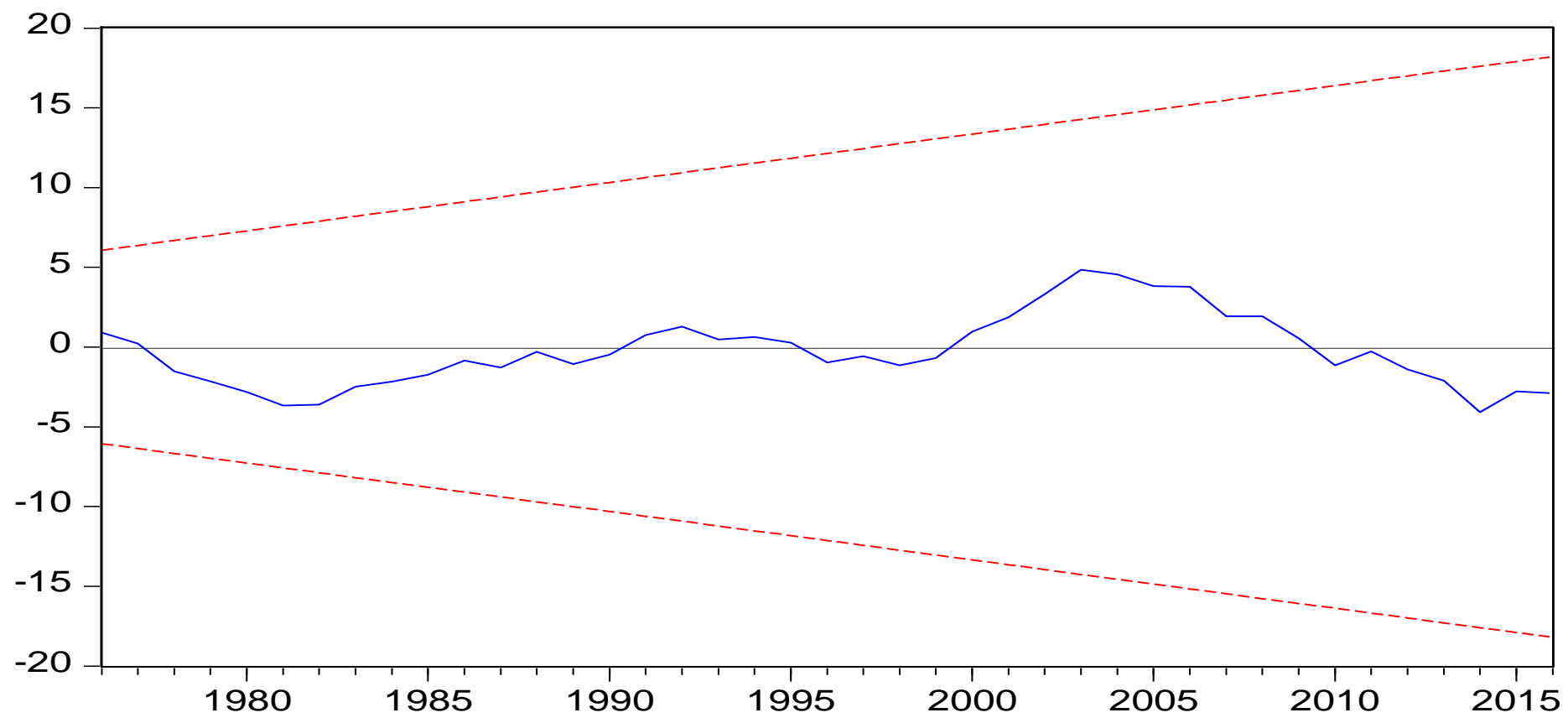

Source: Researcher's Sketch, 2018

Table 3.2.2 Wald Test

Wald Test:

Equation: Untitled

\begin{tabular}{|c|c|c|c|}
\hline \\
\hline Test Statistic & Value & df & Probability \\
\hline $\begin{array}{l}\text { F-statistic } \\
\text { Chi-square }\end{array}$ & $\begin{array}{l}1.797849 \\
5.393546\end{array}$ & $(3,41)$ & $\begin{array}{l}0.1627 \\
0.1451\end{array}$ \\
\hline \multicolumn{4}{|c|}{$\begin{array}{l}\text { Null Hypothesis: } C(9)=C(10)=C(11)=0 \\
\text { Null Hypothesis Summary: }\end{array}$} \\
\hline \multicolumn{2}{|c|}{ Normalized Restriction $(=0)$} & Value & Std. Err. \\
\hline \multicolumn{2}{|l|}{$\begin{array}{l}C(9) \\
C(10) \\
C(11)\end{array}$} & $\begin{array}{r}-13.37116 \\
7.122575 \\
-0.091564\end{array}$ & \begin{tabular}{|l}
5.914892 \\
3.074411 \\
0.290428
\end{tabular} \\
\hline
\end{tabular}

Source: Researcher's Computation, 2018 
Based on the findings of the error correction model, there is a positive and statistically significant relationship between infant mortality rate and total fertility rate in the short-run. A decline in total fertility rate reduces infant mortality rate or crude death rate. The stability of the model using the cusum test indicate that the error correction model is stable since the blue line falls within the boundaries of the red lines as seen in figure 3 above. The LM Test also reveals that the ECM is serially uncorrelated or no serially correlation since the probability value of 0.7822 is more 5\% asymptotic critical level. The analysis reveals that since 1960, the total fertility rate reduce dramatically and this has led to the decline in the infant mortality rate. The fact that the error correction term is negative (0.091564 ) and t-statistics of 0.7542 reveals that it is statistically significant that the model has a stable equilibrium.

\subsection{Results of Multiple Correlation Coefficients}

This part presents the results of multiple correlation coefficients to establish the relationship between infant mortality rate and total fertility rate in Ghana from 1960 to 2016.

Table 3.3. MultipleCorrelation Coefficient

\begin{tabular}{|c|c|c|c|}
\hline Variables & $\begin{array}{c}\text { CRUDE_BIRTH_RA } \\
\text { TE }\end{array}$ & $\begin{array}{c}\text { INFANT_MORTALITY_R } \\
\text { ATE }\end{array}$ & $\begin{array}{c}\text { TOTAL_FERTILITY_RA } \\
\text { TE }\end{array}$ \\
\hline CRUDE_BIRTH_RATE & 1.000000 & 0.997598 & 0.990100 \\
\hline $\begin{array}{c}\text { INFANT_MORTALITY_R } \\
\text { ATE }\end{array}$ & 0.997598 & 1.000000 & 0.991049 \\
\hline $\begin{array}{c}\text { TOTAL_FERTILITY_RAT } \\
\text { E }\end{array}$ & 0.990100 & 0.991049 & 1.000000 \\
\hline
\end{tabular}

Source: Researchers' Computation, 2018

From the table 3.3. above, the analysis of the multiple correlation coefficients suggest that infant mortality rate (IMR) and total fertility rate (TFR) in Ghana shows a perfect positive correlation coefficient of 0.9910049 meaning that they have a direct relationship such that the values of IMR and TFR increase or decrease together. Hence, the analysis of IMR and TFR of Ghana from 1960 to 2016 reveals a high perfect correlation and the crude birth rate also shows a perfect positive correlation with IMR with a correlation coefficient of 0.997598 . This simply means that the rate of decline in infant and childhood mortality is as a result of tremendous reduction on fertility and crude birth rate and more might be expected as hording behaviour diminishes overtime. The results from 1960 to 2016 suggest that Ghana is now at low levels of fertility rate which has a declining impact on IMR.

\section{Conclusion:-}

In conclusion, from the trend analysis of the time series data, the results suggest that both total fertility rate and infant and childhood mortality have declined since 1960 to 2016. This could be attributed to both national and international policies and programmes such as family planning method, good healthcare system earmarked by government, WHO and UN to arrest infant mortality as well as natural phenomena on the rate of decline on fertility rate by child bearing women in Ghana. However, the pairwise Granger Causality test shows that infant mortality does Granger cause total fertility rate and thus indicates a unidirectional causality meaning that changes in the rate of fertility causes infant mortality to increase or decrease overtime. Also, the error correction model reveals a positive long-run relationship between infant mortality rate and total fertility rate. Even though, the error correction term is negative, IMR and TFR has a stable equilibrium in the long-run. Notwithstanding, the multiple correlation coefficients indicate that IMR and TFR are positively correlated and have a direct impact on each other. This means that the rate of increase or decrease in total fertility will leads to a tremendous increase or decrease in infant mortality rate. In this study, the rate of decline on Ghana's total fertility rate led to a sharp reduction on infant and childhood mortality rate from 124.2 per 1000 birth in 1960 to 37.2 per 1000 live births in 2016 and this might be expected as hording behaviour diminishes overtime.

\section{References:-}

1. Asefa, M., Drewett, R., \&Tessema, F. (2000). A birth cohort study in South-West Ethiopia to identify factors associated with infant mortality that are amenable for intervention. Ethiopian Journal of Health Development, 14(2). 
2. Galloway, P. R., Lee Ronald D, \&Hammel, E. A. (1998). Infant Mortality and the Fertility Transition: Macro Evidence from Europe and New Findings from Prussia. In From Death to Birth: Mortality Decline and Reproductive Change (pp. 182-226). Washington, DC: The National Academies Press. http://doi.org/10.1093/ije/dyq195

3. Granger, C. W. J. (1969). Investigating Causal Relations by Econometric Models and Cross-spectral Methods. Econometrica, 37(3), 424.

4. Hanes, M. R. (1998). The Relationshpbetween Infant and Child Mortality and Fertility: Some Historical and Contemporary Evidence for the United States. In M. R. Montogomery\& B. Cohen (Eds.), From Death to Birth : Mortality Decline and Reproductive Change (pp. 227-253). Washington, DC: The National Academies Press. http://doi.org/10.1093/ije/dyq195

5. Hussein, M. A. (1993). Time series analysis for forecasting both fertility and mortality levels in Egypt until year 2010. The Egyptian Population and Family Planning Review, 27(2), 67-81.

6. J.M, M.-B. (1977). Relationships between fertility, child mortality and nutrition in Africa. Paris, France, Development Centre of the Organization for Economic Co-operation and Development. Retrieved from https://www.popline.org/node/436742

7. Kirk, D. (1996). Demographic Transition Theory. Population Studies, 50(3), 361-387.

8. Madise, N., Nyarko, P., \& Diamond, I. (2016). Child Loss and Fertility Behaviour in Ghana. Retrieved from https://www.researchgate.net/publication/279685779_Child_loss_and_fertility_behaviour_in_Ghana

9. Palloni, A., \&Rafalimanana, H. (1999). The Effects of Infant Mortality on Fertility Revisited: New Evidence from Latin America. Demography, 36(1), 41-58.

10. Rahman, S., \& Ansari, W. El. (1800). Neonatal Mortality: Incidence, Correlates and Improvement Strategies. British Medical Journal. Retrieved from http://www.bmj.com/content/bmj/336/7635/85.full.pdf

11. Soest, A. Van, \&Saha, U. R. (2018). Relationships between infant mortality, birth spacing and fertility in Matlab, Bangladesh. PLoS ONE, 13(4), 1-21.

12. The World Bank. (2017). Fertility rate, total (births per woman). Retrieved October 25, 2018, from https://data.worldbank.org/indicator/SP.DYN.TFRT.IN

13. Thomas, R. L. (Richard L. (1997). Modern econometrics : an introduction. Harlow, England ; Reading, Mass: Addison-Wesley.

14. Trussell, J., \& Olsen, R. (1983). Evaluation of the Olsen technique for estimating the fertility response to child mortality. Demography, 20(3), 391-405.

15. VanGinneken, J., Bairagi, R., de Francisco, A., Sarder, A. ., \& Vaughan, P. (1998). Health and Demographic Surveillance in Matlab: Past, Present and Future. (G. Duffy, Ed.). Dhaka: International Center for Diarrhoeal Disease Research. Retrieved from http://dspace.icddrb.org/jspui/bitstream/123456789/6688/1/Past_Present_Future1978.pdf

16. WHO. (2018a). Global Health Observatory (GHO) data: Causes of child mortality. Retrieved October 21, 2018, from http://www.who.int/gho/child_health/mortality/causes/en/

17. WHO. (2018b). Global Health Observatory (GHO) data: Infant mortality. Retrieved October 21, 2018, from http://www.who.int/gho/child_health/mortality/neonatal_infant_text/en/

18. WHO. (2018c). Global Health Observatory (GHO) data: Under-five mortality. Retrieved October 21, 2018, from http://www.who.int/gho/child_health/mortality/mortality_under_five/en/

19. World Bank. (2018a, May 16). Crude Birth Rate for Ghana [SPDYNCBRTINGHA]. Retrieved October 28, 2018, from https://fred.stlouisfed.org/series/SPDYNCBRTINGHA

20. World Bank. (2018b, May 16). Fertility Rate, Total for Ghana [SPDYNTFRTINGHA]. Retrieved October 28, 2018, from https://fred.stlouisfed.org/series/SPDYNTFRTINGHA

21. World Bank. (2018c, September 27). Infant Mortality Rate for Ghana [SPDYNIMRTINGHA]. Retrieved October 28, 2018, from https://fred.stlouisfed.org/series/SPDYNIMRTINGHA. 